\title{
Age, body mass and environmental variation shape the foraging ontogeny of Galapagos sea lions
}

\author{
Jana W. E. Jeglinski ${ }^{1}$, Christiane Werner $^{2}$, Patrick W. Robinson ${ }^{3}$, Daniel P. Costa ${ }^{3}$, \\ Fritz Trillmich ${ }^{1}$
}

\author{
${ }^{1}$ Department of Animal Behaviour, University of Bielefeld, 33615 Bielefeld, Germany \\ ${ }^{2}$ Department of Experimental and Systems Ecology, University of Bielefeld, 33615 Bielefeld, Germany \\ ${ }^{3}$ Department of Ecology and Evolutionary Biology, University of California, Santa Cruz, 95060 California, USA
}

\begin{abstract}
Size- and age-specific physiological constraints coupled with inexperience make the transition to independent foraging in juvenile divers a crucial period with important consequences for survival, dispersal and future reproduction. Variation in environmental conditions and associated changes in food availability can additionally constrain the juvenile's development to independence. Juvenile Galapagos sea lions Zalophus wollebaeki (GSL) represent an extreme example of these constraints owing to a low growth rate, seasonal variation in food abundance and unpredictable declines in food availability during El Niño events. Time-depth recorder (TDR) data and stable isotope data of $\delta^{15} \mathrm{~N}$ and $\delta^{13} \mathrm{C}$ of known age juvenile GSL were analysed to investigate the development of diving and foraging, and a regular year was compared with an El Niño year to determine the effect of environmental change on the foraging behaviour of juvenile and adult GSL. GSL juveniles started diving activity at $12 \mathrm{mo}$ of age and showed distinct juvenilespecific diving strategies that suggest there is an ontogenetic niche shift between juvenile and adult GSL foraging. Successful independent foraging, indicated by a strong decrease in $\delta^{15} \mathrm{~N}$ ratio, started considerably later (at 18 mo of age) and was further delayed in the El Niño warm season, indicating there is an even longer dependency on maternal milk during environmentally adverse conditions. Our results suggest that prolonged maternal energetic investment buffers GSL juveniles against the constraints of diving and foraging under environmentally variable conditions and is linked to the low reproductive rate of this species.
\end{abstract}

KEY WORDS: Ontogenetic foraging niche - Diving development - Stable isotope analysis . Time-depth recorder · Environmental variability $\cdot$ El Niño $\cdot$ Zalophus wollebaeki $\cdot$ Life history

\section{INTRODUCTION}

The shift from complete reliance on parental care to self-sufficient foraging marks a crucial transition in the life history of juvenile animals. At this stage juveniles are subjected to challenges and constraints that ultimately affect their fitness and survival (Heinsohn 1991, Sol et al. 1998, Daunt et al. 2007). Owing to their inexperience, young animals are often inefficient foragers and need to compensate for their reduced foraging success with an energetically costly increase in foraging effort (Weathers \& Sullivan 1989, Daunt et al. 2007, Thornton 2008). The lack of foraging skills also makes juveniles poor competitors, especially when competing against adults of other species that are of similar size, and negatively affects juvenile foraging success in competitive situations (Scott 1980, Sol et al. 1998). This is especially problematic for juvenile mammals whose mass at weaning is often lower than adult mass and who often have not completed their morphological and physiological development. Incomplete morphological de- 
velopment can inhibit the handling of larger-sized prey items (Brito 2004, La Croix et al. 2011) or the digestion of specific prey items (Munn \& Dawson 2006), thus narrowing the choice of suitable prey, which in turn leads to differences in resource utilisation and foraging habitat between juveniles and adults (Wikelski \& Trillmich 1994, Page \& McKenzie 2005). Physiological limits (e.g. insufficient development of thermoregulatory abilities) can restrict the duration of sojourns in thermally unfavourable habitats (Donohue et al. 2000, Duchamp et al. 2002). All these behavioural, morphological and physiological constraints on juveniles lead to increased energetic costs that are unfavourably coupled with high energetic demands due to growth and a higher massspecific metabolic rate (Schmidt-Nielsen 1984, Munn \& Dawson 2003).

Owing to the tight energetic budget at the onset of nutritional independence, juvenile foragers are particularly sensitive to environmental variability. Decreases in the distribution and abundance of food resources affect juveniles disproportionately compared with adults by enhancing the negative impacts of juvenile-specific constraints, which affects juvenile growth and development and ultimately results in greater juvenile mortality (Owen-Smith 1990, Singer et al. 1991). Conversely, increases in food abundance can positively influence juvenile growth and survival (McMahon \& Burton 2005).

Juvenile marine mammals experience morphological and physiological limitations and resulting energetic constraints in particular, because diving and foraging duration is limited by the amount of oxygen that can be stored in the lungs, blood (haemoglobin) and muscle (myoglobin) relative to their metabolic demands (Burns et al. 2005). As oxygen stores and their effective use increase with age and body size, physiological development largely determines the possibility of underwater foraging activity (Horning \& Trillmich 1997a, Burns et al. 2005, Richmond et al. 2006, Fowler et al. 2007b, Weise \& Costa 2007). Owing to these constraints, most juvenile pinnipeds employ diving and foraging patterns that diverge from those of adults in either prey choice (Page \& McKenzie 2005), foraging locations (Fowler et al. 2007a) or dive depth and duration (Horning \& Trillmich 1997b, Fowler et al. 2006, Spence-Bailey et al. 2007, Lea et al. 2010). The distribution and abundance of suitable prey and the productivity and predictability of the marine habitat, therefore, have an important effect on juvenile pinniped growth, the developmental rate to independent foraging, and juvenile survival (Craig \& Ragen 1999, Horning \&
Trillmich 1999, Trites \& Donnelly 2003). In otariid seals for example, time to weaning and nutritional independence ranges from 4 mo in subpolar species (seasonally highly productive habitats) to about 12 mo in temperate species (less productive environments) and does not occur until 24 to 36 mo in equatorial species (seasonally highly variable and generally less productive habitat) (Doidge \& Croxall 1989, Costa 1991, Horning \& Trillmich 1997b, Lea et al. 2010)

Otariid females employ a foraging cycle lactation strategy, during which juveniles can develop independent foraging gradually while being supported by maternal milk (Costa 1991, Burns et al. 2004). This enables mothers to buffer the critical phase of early juvenile foraging but, owing to energetic trade-offs, decreases maternal investment in future reproduction (Trivers 1974, Trillmich \& Wolf 2007). The fact that mothers pay these costs suggests that a long period of partial dependence on milk and selfdependent foraging is of major benefit to the juveniles and ultimately to the reproductive success of the mother. The considerable duration of the dependency period in juveniles of some otariid species implies a certain period of overlap in maternal provisioning and juvenile foraging. The relative contributions to the energy budget of juvenile otariids and factors influencing those remain poorly studied, but are crucial in understanding life history patterns and population dynamics, especially in species that are exposed to enhanced environmental variation associated with climate change.

In recent years, stable isotope analysis has become a powerful tool in the study of trophic ecology (Post 2002, Newsome et al. 2007, 2010). Stable nitrogen isotope ratios increase in a predictable way between diet and consumer owing to enrichment of the heavier isotope, with an increase in $\delta^{15} \mathrm{~N}$ of about $3 \%$ per trophic level (DeNiro \& Epstein 1981, Minagawa \& Wada 1984, Post 2002, Newsome et al. 2006). Milk consumption leads to a similar enrichment between mother and offspring because the offspring consumes maternal milk that is produced through the remobilization of maternal tissue (Hobson et al. 1997, Newsome et al. 2006). Fully dependent offspring therefore occupy higher trophic positions and have enriched stable nitrogen isotope values compared to their mothers (Hobson et al. 1997, Jenkins et al. 2001, Fuller et al. 2006). At the onset of independent foraging, offspring change their main nutritional source from higher trophic level milk to lower trophic level prey. In this way, decreasing offspring $\delta^{15} \mathrm{~N}$ values trace the cessation of suckling and the onset of inde- 
pendent foraging (Balasse 2001, Dalerum et al. 2007). It is therefore possible to investigate the relative contribution of maternal milk and independent foraging by $\delta^{15} \mathrm{~N}$ analysis of juveniles. So far, diving abilities and trophic position have not been studied simultaneously in juvenile otariids. Changes in trophic position tell us if and when juveniles are successfully able to sustain themselves nutritionally. On the other hand, changes in diving behaviour show how they achieve this crucial goal and when physiological development enables them to attempt independent foraging. Thus, combining these 2 sources of information allows a more substantial interpretation of the processes that influence the transition from milk dependence to self-sustaining foraging, which has major implications for juvenile survival and recruitment and in turn for the dynamics of the population.

The Galapagos sea lion Zalophus wollebaeki (GSL) provides an ideal system for investigating juvenile foraging development by using the combination of both methodologies. GSL present a case of extreme and variable prolongation of maternal care (Trillmich 1990, Trillmich \& Wolf 2007, Mueller et al. 2011). Lactation lasts on average about $2 \mathrm{yr}$, but can be prolonged considerably (Trillmich 1990, Trillmich \& Wolf 2007), up to 5 yr (B. Mueller, K. Meise \& F. Trillmich unpubl. data). However, there is a clear lack of understanding of the factors modulating this high variability in the duration of lactation and dependency of juveniles.

Adult GSL females are extreme divers despite their comparably small body size and dive routinely to very great depths (Villegas-Amtmann \& Costa 2010; maximum depth recorded $584 \mathrm{~m}, \mathrm{~J}$. W. E. Jeglinski unpubl. data) and their total body oxygen stores are the highest reported for otariids (Trillmich et al. 2008, Villegas-Amtmann \& Costa 2010). Juvenile GSL grow at an exceptionally slow rate (Mueller et al. 2011), and achieving adult performance therefore is probably a long process for a juvenile diver.

Additionally, GSL are nonmigratory and therefore cannot escape from the seasonal variations in productivity of the Galapagos marine ecosystem. Furthermore, sporadically occurring El Niño events that lead to increased sea surface temperatures (SST) and catastrophic reductions in food availability affect juvenile growth and can cause considerable juvenile mortality (Trillmich \& Limberger 1985, Trillmich \& Dellinger 1991, Mueller et al. 2011). Thus, the susceptibility of GSL to El Niño events makes them a sensible case study to monitor the implications of global climate change that possibly increase both frequency and intensity of El Niño events (Trenberth
\& Hoar 1997, Houghton et al. 2001). However, this requires a profound knowledge of the interplay between constraints for juvenile foragers during development, maternal investment and varying environmental conditions.

GSL juveniles are an excellent example of a highly constrained juvenile forager, where major limitations in a difficult and stochastic environment are buffered by prolonged maternal care. Using this exceptional system, we sought to answer the following questions: (1) When do GSL juveniles start diving? (2) When and to what extent do juvenile GSL begin to supplement their energy intake through independent foraging? (3) Does the foraging niche of juvenile GSL differ from that of adults? (4) How is the development of diving and independent foraging in GSL juveniles affected by environmental variability?

\section{MATERIALS AND METHODS}

\section{Study species, environmental conditions and study site}

GSL are endemic to the Galapagos Islands. The archipelago, approximately $1000 \mathrm{~km}$ west of Ecuador, is characterised by a pronounced seasonality of food abundance; throughout the first half of the year, SST is approximately $25^{\circ} \mathrm{C}$ and decreases owing to increased upwelling during the second half of the year, from August to December, to values around $21^{\circ} \mathrm{C}$ (Palacios 2004). These seasonal SST changes are linked to changes in primary productivity. As a result, a distinct warm season with low marine productivity and food abundance prevails during the first half of the year and a cold season with increased productivity covers the second half of the year (Fiedler 1994). The breeding season of GSL falls in the cold, productive season and pup births peak around the end of October and early November in the colonies in the central part of the archipelago (Pörschmann et al. 2010).

Occasional, unpredictable catastrophic El Niño events alter the regular, seasonal shift of marine conditions drastically, leading to exceptionally high SST and low marine primary productivity (Feldman et al. 1984, Barber \& Chavez 1983), causing severe problems for marine foragers (Trillmich \& Limberger 1985, Anderson 1989).

Data were collected between September 2008 and May 2010 in the sea lion colony Loberia Post Office Bay $\left(01^{\circ} 13^{\prime} 37^{\prime \prime} \mathrm{S}, 90^{\circ} 26^{\prime} 38^{\prime \prime} \mathrm{W}\right)$, a small islet on the northern coast of Floreana Island (Fig. 1). The colony 


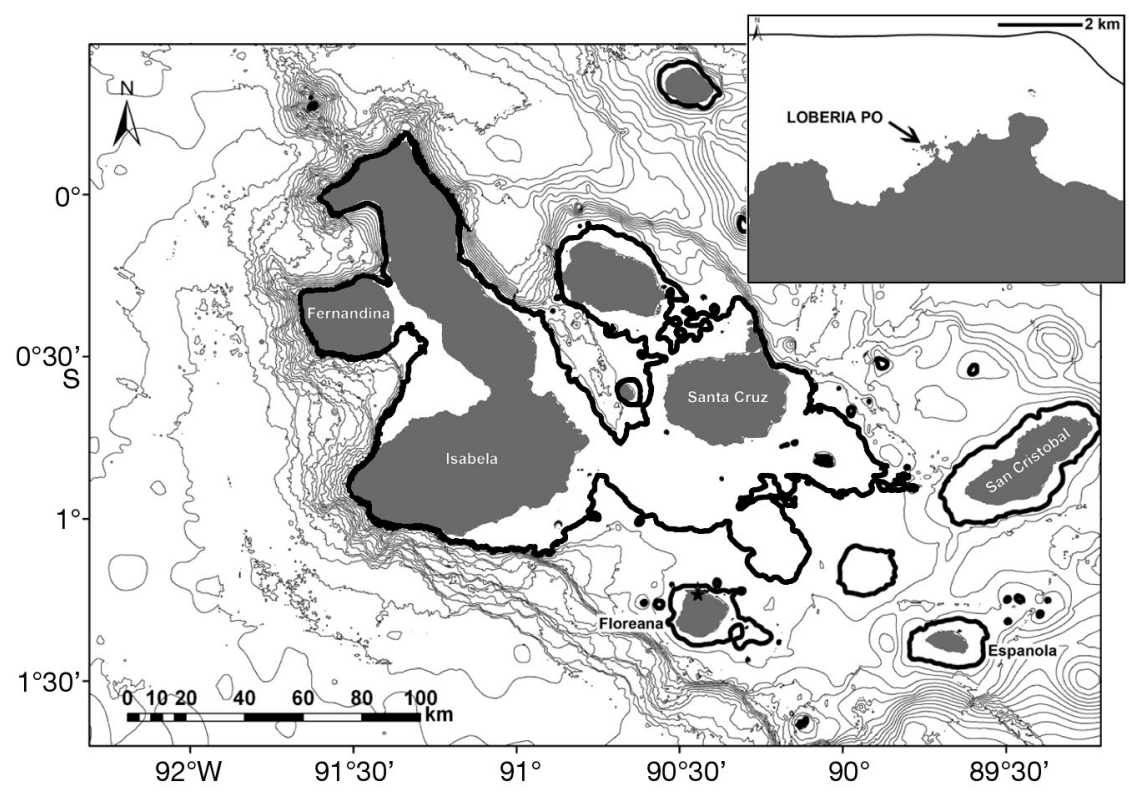

Fig. 1. The Galapagos Islands archipelago and the study GSL colony at the Loberia Post Office site (LOBERIA PO, star) at Floreana Island. Thick black lines indicate the extent of the continental shelf; bathymetrical contours beyond the shelf are spaced in $200 \mathrm{~m}$ intervals. Bathymetrical data were collected by Geist et al. (2006), accessed through the Marine Geoscience Data System (MGDS), Lamont-Doherty Earth Observatory, Columbia University, New York, and assembled using GeoMappApp 3.0.0

cohort of known age was established by capturing juveniles in October 2008 and calculating their age by using species-specific age estimation equations based on morphometric and teeth measurements (Jeglinski et al. 2010). Twenty-two sea lions were calculated to be approximately $12 \mathrm{mo}$ old and were marked with passive transponders and flipper tags.

\section{Time-depth recorder deployment and animal handling}

Instruments were deployed on GSL juveniles in 4 different periods that coincided with peak periods of seasonal changes in SST (cold: October 2008 and October-November 2009; warm: April 2009 and April 2010). Owing to the timing of the reproductive season (cold season: September-January), juveniles of a specific age can only be sampled in either the cold (approximately 12 and $24 \mathrm{mo}$ ) or warm season (approximately 6 or

represents one of the largest GSL breeding colonies in the Galapagos archipelago and has average census numbers of $222 \pm 72.8$ animals (mean $\pm \mathrm{SD}, \mathrm{n}=$ 11, from September 2008 to May 2010, J. W. E. Jeglinski unpubl. data).

\section{Establishment of known-age cohorts}

Thirty-two pups younger than 2 wk were captured as soon as their mothers were absent for the first time after parturition in October 2008. Individuals were marked by clipping numbers into the fur of the lower back and passive transponders (Trovan, Electronic Identification Devices) were subcutaneously inserted into the dorsal neck area just above the shoulder blades. Twenty-two sea lions of the marked cohort were recaptured in the following season (April 2009) when their front flippers had grown large enough to allow tagging. Juveniles were tagged with individually numbered green Allflex plastic tags (tag size 0, Allflex Europe) in the trailing edge of both front flippers. Six additional juveniles that had just moulted into their first juvenile pelage (age about 4 to $6 \mathrm{mo}$ ) were captured and marked with passive transponder and plastic tags to increase the sample size. A second
$18 \mathrm{mo}$ ). We grouped juveniles in age categories (6, 12,18 and $24 \mathrm{mo}$, abbreviated as $6 \mathrm{M}, 12 \mathrm{M}, 18 \mathrm{M}$ and $24 \mathrm{M})$ for further analysis. Adult females were captured in 1 cold season (October to November 2009) and 2 warm seasons (April 2009 and April 2010). All adult females suckled either newborn pups or $6 \mathrm{M}$ juveniles in the cold or warm season, respectively. Nursing females are likely to exhibit foraging behaviour close to their physiological maximum owing to the high energetic demands imposed by the combination of offspring provisioning and self-maintenance and were therefore used as the standard of comparison for dive behaviour.

All GSL were captured with cone-shaped hoop nets, which had a small muzzle opening to facilitate breathing (R. Lohmann tailoring; Animal Capture Equipment), and were manually restrained. Body mass was recorded with a digital scale hanging from a tripod (Kern HUS 300K 100, precision 0.2 kg, maximum capacity $100 \mathrm{~kg}$ ), and morphometric measurements of standard length (SL), fore-flipper length and width (FL, FW) and axillary girth were taken (Jeglinski et al. 2010). Instruments, glued onto neoprene and attached to a piece of black mesh with cable ties, were attached to the dorsal fur on the midline of the back of the study sea lions just below the 
shoulder blades by using fast setting epoxy (Araldite 2012, Huntsmann Advanced Materials). We used MK10-F and MK9, (Wildlife Computers) or Sensus Ultra (ReefNet) temperature and depth recorders (TDRs). Sensus Ultra TDRs provide comparable records to MK9 and MK10 TDRs (Robinson et al. 2009). All TDRs were programmed to sample depth, time and temperature every $2 \mathrm{~s}$. The depth resolution and accuracy was $0.5 \mathrm{~m}$ and $\pm 1 \%$, respectively, for the MK9 and MK10 TDRs and $0.01 \mathrm{~m}$ and $\pm 0.3 \mathrm{~m}$ for the Sensus Ultra TDRs (Robinson et al. 2009). Vehicle-borne high frequency (VHF) transmitters (Sirtrack) were deployed behind TDRs on all animals, except for $6 \mathrm{M}$ juveniles, to facilitate recapture and monitor attendance behaviour. Sets of instruments (TDR and VHF) measured a maximum of $15 \times 6 \times$ $3 \mathrm{~cm}$ (length $\times$ width $\times$ height) and weighed between 0.3 and $0.7 \%$ of the study animal's body weight. The epoxy took $8.9 \pm 2.7$ min to set (mean $\pm \mathrm{SD}, \mathrm{n}=53$ ), after which animals were released. Total handling time from capture to release was $19.2 \pm 9.4 \mathrm{~min}$ ( $\mathrm{n}=$ 52). Instruments were recovered and neoprene mesh mountings were completely removed when the sea lions were recaptured after $7.0 \pm 0.3 \mathrm{~d}$ (mean $\pm \mathrm{SE}$, $\mathrm{n}=78$ ). We recorded the body mass of 19 individuals before and after a TDR deployment as a measure of any short-term effect of TDR deployment. We monitored the study animals in subsequent seasons and found no apparent signs of a negative effect of the TDR deployment on external appearance and behaviour (J. W. E. Jeglinski unpubl. data).

\section{Stable isotope sampling and analysis}

Pinniped skin provides a short-term integration of dietary isotopes ( 2 mo, Kurle \& Worthy 2002) and was collected when the sea lions' flippers were tagged. Skin samples were stored in sterile plastic vials in ethanol $70 \%$ (study period 2008) or air-dried and stored dry (subsequent study periods spring, autumn 2009 and spring 2010). The storage method had no effect on $\delta^{15} \mathrm{~N}$ or $\delta^{13} \mathrm{C}$ signatures (paired $t$-test, $\delta^{15} \mathrm{~N}$ : $\left.t=0.394, \mathrm{p}=0.713 ; \delta^{13} \mathrm{C}: t=0.597, \mathrm{p}=0.583, \mathrm{n}=5\right)$. Further, the mean difference between samples stored either dry or in ethanol of 0.1 and $-0.06 \%$ for $\delta^{15} \mathrm{~N}$ and $\delta^{13} \mathrm{C}$, respectively, was below the range of published measurement errors of 0.3 and $0.1 \%$ for $\delta^{15} \mathrm{~N}$ and $\delta^{13} \mathrm{C}$, respectively (Habran et al. 2010, Lowther \& Goldsworthy 2011).

We extracted lipids from skin samples following Dobush et al. (1985) and Kurle \& Worthy (2002). Briefly, ethanol stored skin pieces were oven dried for $12 \mathrm{~h}$ at $40^{\circ} \mathrm{C}$. All dry skin samples were inspected for attached debris and rinsed with distilled water. Skin pieces were soaked in petroleum ether for $24 \mathrm{~h}$, changing the petroleum ether once after $12 \mathrm{~h}$. The samples were then soaked for $12 \mathrm{~h}$ in distilled water, which was replaced after $8 \mathrm{~h}$, and finally oven-dried at $40^{\circ} \mathrm{C}$ for $12 \mathrm{~h}$. Samples of about $0.35 \mathrm{mg}$ of dried skin were loaded into tin capsules, combusted under $\mathrm{O}_{2}$ excess in an elemental analyser (EuroVector EA, Hekatech) and converted to $\mathrm{CO}_{2}, \mathrm{~N}_{2}$ and $\mathrm{H}_{2} \mathrm{O}$. After removing $\mathrm{H}_{2} \mathrm{O}$ with a water trap, the combustion products were flushed in a helium stream through the dilutor box into the isotope ratio mass spectrometer (ISOPRIME, Elementar), which was coupled via a variable open-split interface to the elemental analyser. Samples were standardised to IAEA-N2 and IAEA-CH-6 (International Atomic Energy Agency) and an IVA protein standard. Repeated measurement precision was $0.12 \%$ and $0.14 \%$ for $\delta^{13} \mathrm{C}$ and $\delta^{15} \mathrm{~N}$, respectively. Carbon and nitrogen isotope ratios are reported relative to VPDBee and atmospheric air, respectively, and expressed as $\delta$-notation (in \%o) determined from the following equation:

$$
\delta^{A} X=\left(\frac{R_{\text {sample }}}{R_{\text {standard }}}-1\right) \times 1000
$$

where $R_{\text {sample }}$ and $R_{\text {standard }}$ are the ratios of the heavier to the lighter isotope of the sample and the standard, respectively, $A$ is the mass number (13 for $C$ and 15 for $\mathrm{N}$ ) and $X$ is the element ( $\mathrm{C}$ or $\mathrm{N}$ ) considered.

\section{Dive analysis}

Zero offset correction was performed with a purpose written MatLab toolbox (IKNOS, Y. Tremblay unpubl.), and a dive summary file for each individual deployment that contained date, time, maximum depth, duration and bottom time for each dive was created using a minimal depth of $5 \mathrm{~m}$ and minimal duration of $12 \mathrm{~s}$ (Villegas-Amtmann et al. 2008). Bottom time was defined as the time individuals spent at between 80 and $100 \%$ of the maximum depth of a specific dive and is commonly assumed to be the time when foraging takes place. We did not filter travelling dives as has been done previously (VillegasAmtmann et al. 2008, Villegas-Amtmann \& Costa 2010), because there was no objective criterion to distinguish between shallow foraging dives and shallow travelling dives. We determined wet and dry periods from wet/dry sensor data of TDRs by using a custom written MatLab function (P. Robinson unpubl.) and calculated the time at sea (TAS) as the 
proportion of the sum of all wet periods exceeding 10 min divided by the deployment time (SpenceBailey et al. 2007). Total time spend diving (TSD) was calculated as the proportion of the sum of all dive durations divided by the total time at sea. Vertical distance travelled (VTD) was calculated as the sum of the depths of all dives $\times 2$ (vertical distance travelled to and from depths) divided by the deployment period in days. The total time at bottom (TAB) was calculated as the proportion of the sum of all bottom time durations to the sum of all dive durations. Trip durations were calculated based on a minimum continuous wet period exceeding $45 \mathrm{~min}$ in accordance with Villegas-Amtmann et al. (2008). Dive rate was calculated as number of dives per hour. Diel activity was calculated based on an equatorial $12 \mathrm{~h}$ day with the periods of time between 06:00 and 18:00 h defined as day and between 18:01 and 05:59 $\mathrm{h}$ as night.

\section{Data analyses}

To describe the general pattern of juvenile diving behaviour and compare juvenile with adult diving behaviour and stable isotope signatures, we analysed diving behaviour and stable isotope signatures of $6 \mathrm{M}, 12 \mathrm{M}, 18 \mathrm{M}$ and $24 \mathrm{M}$ GSL, as well as of adult female GSL, by using data from 2 regular cold seasons (October 2008, October-November 2009) and 1 regular warm season (April 2009). Diving behaviour (ANOSIM, global $\mathrm{R}=0.025, \mathrm{p}=0.312$ ) and stable isotope signatures $\left(t\right.$-test, $\delta^{15} \mathrm{~N}: t_{2,12}=1.011, \mathrm{p}=0.332$; $\delta^{13} \mathrm{C}: t_{2,12}=1.109, \mathrm{p}=0.289$ ) of adult females did not differ significantly between the warm and the cold seasons of 2009, so female data from both seasons were pooled for the following analyses.

The 2010 warm season was classified as a mild El Niño (Climate Prediction Center, NOAA, April 2010). A comparison of daily SST values (Charles Darwin Research Station in Bahia Academia, Puerto Ayora, Galapagos Islands) showed that April 2009 was significantly cooler than the El Niño April 2010 $\left(25.6 \pm 0.5^{\circ} \mathrm{C}\right.$ [mean $\pm \mathrm{SD}$ ] and $28.1 \pm 1.6^{\circ} \mathrm{C}$, respectively; Wilcoxon test, $W=57.5, \mathrm{p}<0.01$ ). Therefore, we compared diving behaviour and stable isotope signatures of $18 \mathrm{M}$ juveniles and adult females sampled in the normal warm season (April 2009) with those of both age categories sampled during the El Niño warm season (April 2010) to investigate the possible influence of increased SST and decreased food abundance on the foraging behaviour of juvenile and adult GSL.

\section{Statistical analyses}

We used analysis of similarity (ANOSIM) on BrayCurtis similarities of 15 dive variables (see Table 2 values marked with ${ }^{*}$, see Tables $2 \& 3$ ) to investigate overall differences in diving performance of all study animals (Primer-e, PML). The significance of the ANOSIM tests was based on 9999 permutations. Between-group dissimilarities were tested by using ANOSIM tests and p-values were corrected for multiple testing by using Bonferroni corrections. The contribution of individual dive variables to dissimilarity pattern was investigated by using BEST test in Primer. All statistical analyses apart from ANOSIM were performed by using R 2.11.1 (R Development Core Team 2010).

We used a principal component analysis (PCA) to merge the 15 dive variables to fewer, uncorrelated components to determine the influence of age, sex and body mass on different aspects of juvenile diving behaviour. A small number of juveniles were resampled at different ages. We therefore ran linear mixedeffect models (LMEs; package nlme) by using diving principal components as the response variable and animal ID as a random factor to account for nonindependence. Age category, sex and body mass were used as independent variables to investigate determinants of juvenile diving performance in $12 \mathrm{M}$, $18 \mathrm{M}$ and 24M GSL. We used an information theoretical approach (Burnham \& Anderson 2002) by fitting a null model and all possible combinations of explanatory variables. Corrected Akaike's information criteria $\left(\mathrm{AIC}_{\mathrm{c}}\right)$ were used for model selection to account for small sample sizes. Models with $\mathrm{AIC}_{\mathrm{c}}$ differences of $<2$ were considered the best among the set of fitted models (Burnham \& Anderson 2002); $\mathrm{AIC}_{\mathrm{c}}$ weights ( $\mathrm{wAIC}_{\mathrm{c}}$ ) as proportional weight of evidence in support of the particular models were calculated for additional support (see Table 4). To investigate the trophic position of juvenile and adult GSL and to detect differences among juvenile age categories, we fitted LME models by using stable nitrogen signature as the response variable, age category as the independent variable and animal ID as a random factor. We correlated the principal dive components with stable nitrogen values of juveniles to investigate the relationship between food intake by foraging and diving performance.

For the comparison of a regular and an El Niño warm season, we used ANOSIM to test for seasonal differences in diving performance of 18M GSL and adult GSL females based on a similarity matrix of 18 dive variables (additional variables were mean depth 
at day and at night and maximum dive rate, see Table 2 values marked with + ). Stable nitrogen and stable carbon signatures of 18M GSL and adult females were compared by using $t$-tests to investigate possible seasonal differences. Data were visually inspected and tested for normality using the Shapiro-Wilk test and for homogeneity of variances using Breusch-Pagan tests. Data are presented as mean $\pm \mathrm{SE}$ if not stated otherwise, and results are considered significant at the $\mathrm{p}<0.05$ level.

\section{RESULTS}

We retrieved 78 individual records from 82 deployed TDRs. The mean deployment period was $7.3 \pm$ $0.3 \mathrm{~d}$ and we recorded a total of 53292 dives (Table 1).

Juvenile body mass did not change over the deployment period $(19.6 \pm 2.1$ and $19.6 \pm 2.5 \mathrm{~kg}$ for $6 \mathrm{M}$ animals and $23.5 \pm 1.5$ and $23.8 \pm 1.3 \mathrm{~kg}$ for $12 \mathrm{M}$ animals before and after deployment, respectively; pairwise $t$-test, $t=-0.748, \mathrm{p}=0.464)$. Given the minimal growth that $6 \mathrm{M}$ and $12 \mathrm{M}$ juveniles exhibit during such a short period (Mueller et al. 2011), this suggests that weight and drag imposed by the dive recorder had minimal effects on the sea lions studied.

\section{Development of diving behaviour}

Diving behaviour was characterised by 15 dive variables (Tables $2 \& 3$ ) and differed substantially between the 5 age categories (ANOSIM, global $\mathrm{R}=$ $0.506, \mathrm{p}<0.01)$. The variables contributing most to these differences were maximum diving depth, VTD, maximum trip duration and dive rate $(\mathrm{BEST}$, rho $=$ 0.978, p < 0.01).
In contrast to older age categories, $6 \mathrm{M}$ juveniles were swimmers, not divers (global $\mathrm{R}=1,0.924,0.928$ and 0.850 for adult females and $24 \mathrm{M}, 18 \mathrm{M}$ and $12 \mathrm{M}$ juveniles, respectively, $\mathrm{p}<0.01$ ); they spent $40 \%$ of the deployment period in the water, mostly close to shore (J. W. E. Jeglinski pers. obs.), but only $1 \%$ of that time diving (TSD, Table 2). One 6M juvenile did not dive at all and the remaining nine $6 \mathrm{M}$ individuals dived rarely and briefly below the $5 \mathrm{~m}$ threshold (Table 2). Sex had no influence on any of the dive characteristics of $6 \mathrm{M}$ juveniles ( $t$-test, $\mathrm{p}>0.05$ ). Body mass was significantly positively correlated with TAS (Pearson's $r=0.6987, p=0.036$ ), but did not influence any other dive characteristic (Pearson correlations, $\mathrm{p}>0.05)$.

In contrast to $6 \mathrm{M}$ juveniles, $12 \mathrm{M}, 18 \mathrm{M}$ and $24 \mathrm{M}$ juvenile sea lions showed substantial diving activity (Table 2). The deepest dives recorded reached 367.0, 297.5 and $358.5 \mathrm{~m}$ in $12 \mathrm{M}, 18 \mathrm{M}$ and $24 \mathrm{M}$ old juveniles, respectively. Despite these impressive maximum depths, the diving behaviour of all juvenile divers differed significantly from that of adult females (12M: global $\mathrm{R}=0.512, \mathrm{p}<0.01 ; 18 \mathrm{M}$ : global $\mathrm{R}=$ 0.605, $\mathrm{p}<0.01$; 24M: global $\mathrm{R}=0.273, \mathrm{p}=0.033$ ). Adult females dived approximately $30 \%$ deeper than the deepest diving juveniles (Table 2, deepest depth recorded was $520.5 \mathrm{~m}$ ). Adult female average and maximum trip duration were 5 and $10 \mathrm{~h}$ longer, respectively, than those of juvenile divers. Adult females travelled on average $21.2 \pm 1.6 \mathrm{~km}$ vertically per day, more than twice as much as the highest performing juvenile age category (Fig. 2). Adult female diving activity showed no diel pattern, while all juveniles dived predominately at night (70 to $93 \%$, Fig. 3). All juvenile age classes spend a higher proportion of their total dive time diving at the bottom of dives (Fig. 4), but dived to shallower depths than did adult females, trading off diving depth for bottom time (Fig. 5).

Table 1. Zalophus wollebaeki. Mean deployment period $( \pm \mathrm{SE})$, mean and total number of dives and body mass of sampled GSL age categories (for Galapagos sea lion juveniles given in months). Sample seasons are indicated as cold (autumn 2008 and 2009), warm (spring 2009) and El Niño (spring 2010). M: month

\begin{tabular}{|lcrccrr|}
\hline Age category & Season & $\mathrm{n}$ & Mass $(\mathrm{kg})$ & $\begin{array}{c}\text { Mean deployment } \\
\text { period (d) }\end{array}$ & $\begin{array}{c}\text { Mean no. } \\
\text { of dives }\end{array}$ & $\begin{array}{c}\text { Total no. } \\
\text { of dives }\end{array}$ \\
\hline 6 M juvenile & Warm & 9 & $22.9 \pm 1.4$ & $6.9 \pm 0.9$ & $71.0 \pm 59.5$ & 639 \\
12 M juvenile & Cold & 29 & $26.6 \pm 1.3$ & $7.0 \pm 0.7$ & $871.3 \pm 89.6$ & 25268 \\
18 juvenile & Warm & 8 & $30.6 \pm 1.2$ & $5.9 \pm 0.3$ & $886.6 \pm 128.1$ & 7093 \\
18 M juvenile & El Niño & 5 & $31.4 \pm 4.3$ & $3.0 \pm 0.1$ & $339.4 \pm 78.9$ & 1697 \\
24 juvenile & Cold & 8 & $30.9 \pm 1.2$ & $8.7 \pm 0.8$ & $919.9 \pm 230.1$ & 9303 \\
Adult female & Warm + cold & 15 & $72.9 \pm 3.7$ & $9.9 \pm 0.4$ & $1033.7 \pm 232.7$ & 17519 \\
Adult female & El Niño & 4 & $72.3 \pm 6.4$ & $3.4 \pm 0.6$ & $233.0 \pm 53.0$ & 932 \\
\hline
\end{tabular}


Table 2. Zalophus wollebaeki. Summary of dive variables for all Galapagos sea lion age categories in all sampling seasons. Values are represented as means \pm SE. Variables used for similarity matrix are indicated with *; additional variables used for similarity analysis comparing regular warm season and El Niño warm season are indicated with +. Max: maximum; VTD: sum of vertical distance traveled to and from depths relative to deployment period in days; TAS: time at sea as proportion of deployment time; TSD: time spent diving as proportion of time at sea; TAB: time at bottom of dive as proportion of dive duration; DAN: number of dives performed at night as proportion of total number of dives. M: month

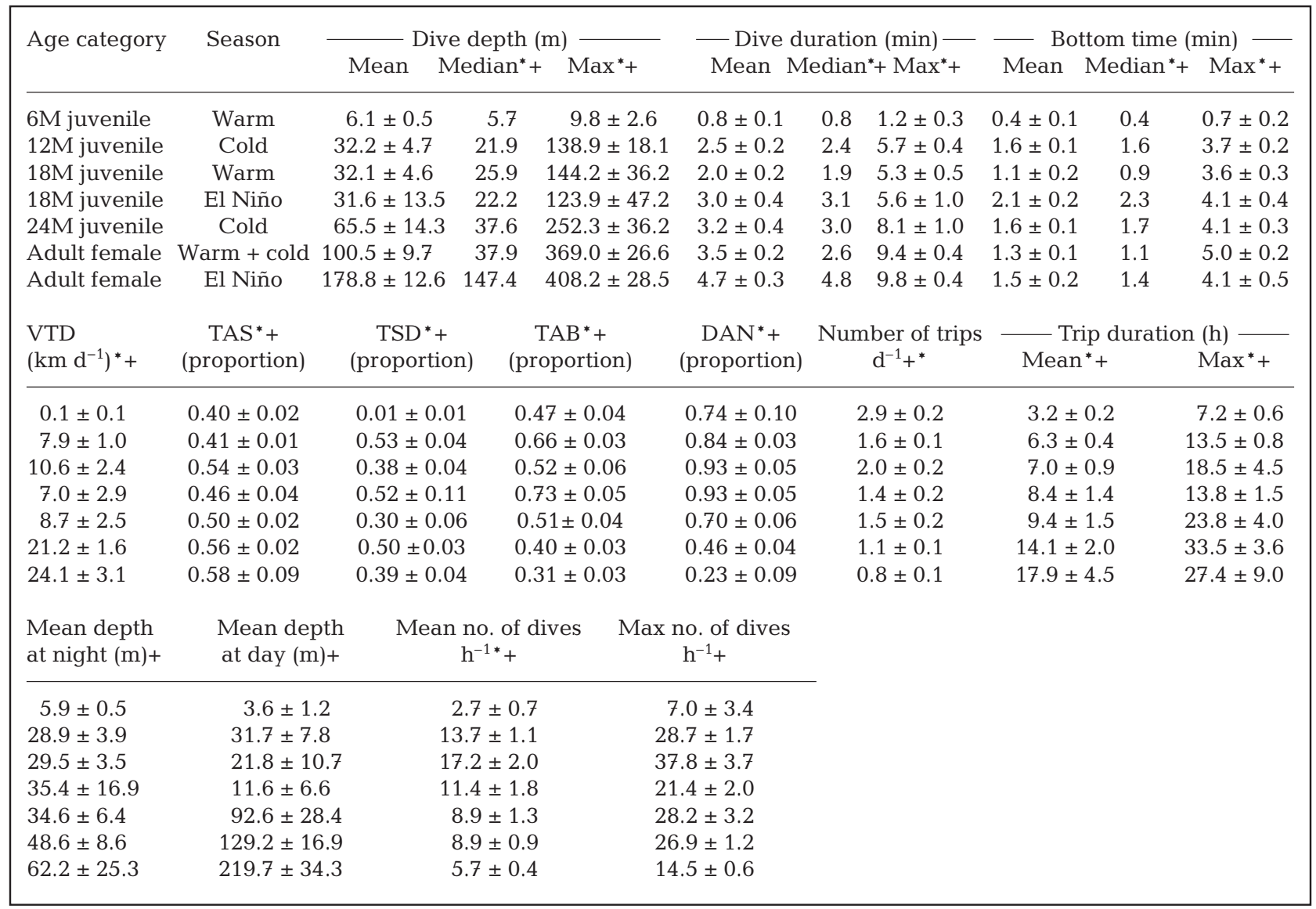

Table 3. Zalophus wollebaeki. Eigenvalues of first 3 principal components used in the PCA of juvenile Galapagos sea lion diving behaviour. For abbreviations see Table 2

\begin{tabular}{|lrrr|}
\hline & PC1 & PC2 & PC3 \\
\hline Cumulative variance explained & $41.4 \%$ & $60.9 \%$ & $73.3 \%$ \\
Median depth & 0.259 & -0.081 & 0.079 \\
Maximum depth & 0.347 & 0.079 & -0.044 \\
Median duration & 0.256 & -0.400 & 0.050 \\
Maximum duration & 0.339 & -0.114 & -0.023 \\
Median bottom time & 0.061 & -0.566 & 0.055 \\
Maximum bottom time & 0.206 & -0.413 & -0.055 \\
VTD & 0.305 & 0.127 & -0.348 \\
TAS & 0.213 & 0.172 & -0.246 \\
TSD & 0.076 & -0.276 & -0.536 \\
DAN & -0.288 & 0.007 & -0.317 \\
TAB & -0.250 & -0.377 & -0.020 \\
No. of trips per day & -0.268 & -0.083 & -0.138 \\
No. of dives per hour & -0.138 & 0.082 & -0.672 \\
Mean trip duration & 0.338 & 0.164 & -0.013 \\
Maximum trip duration & 0.302 & 0.137 & -0.024 \\
\hline
\end{tabular}

\section{Characteristics of juvenile diving}

Juvenile diving behaviour can be characterised by 3 principal components that explained $73 \%$ of the variation (variables and their loadings are listed in Table 3). We fitted linear mixed effects models by using each principal component as a response variable to examine juvenile diving strategy.

The first principal component (PC1) contained the highest loadings for maximum dive depths, maximum dive duration, mean trip duration and VTD (Table 3). Variation in PC1 was best explained by a model containing age and body mass (Table 4). Sex had little influence as the next best model, age + mass + sex, explained approximately $20 \%$ less of the variation $\left(\mathrm{wAIC}_{\mathrm{c}}=0.182\right.$, Table 4$)$. Diving depth, as an important contributor to PC1, was very similar for $12 \mathrm{M}$ and $18 \mathrm{M}$ juveniles, but was significantly higher in $24 \mathrm{M}$ ju- 


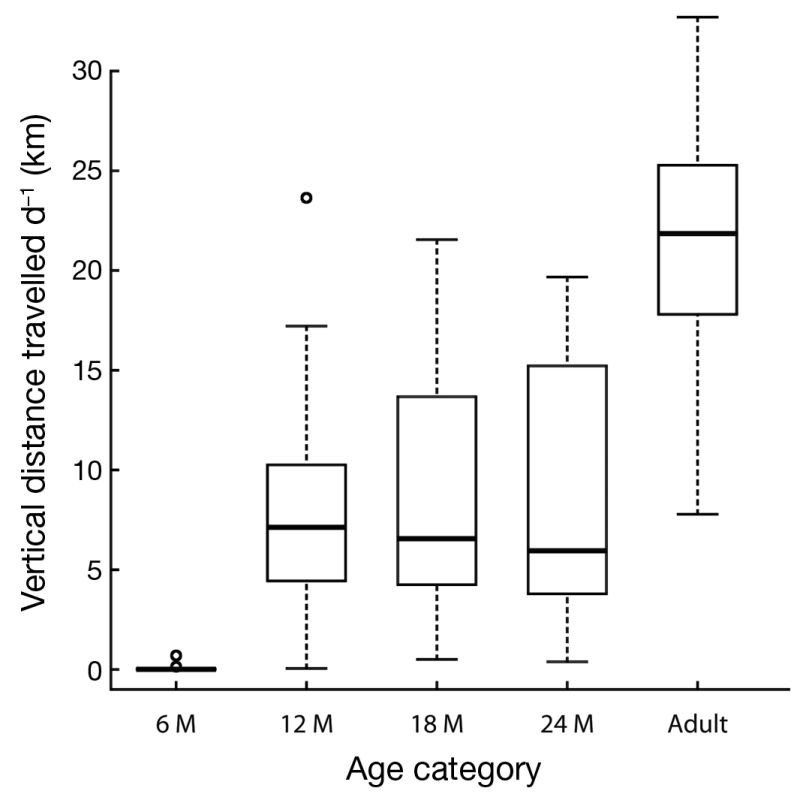

Fig. 2. Zalophus wollebaeki. Vertical distance travelled (sum of diving depth $\times 2$ ) shown as median (line), interquartile range (box) and range (whiskers), as a proxy for dive effort for Galapagos sea lion age categories sampled in the regular cold (autumn 2008 and 2009) and warm (spring 2009)

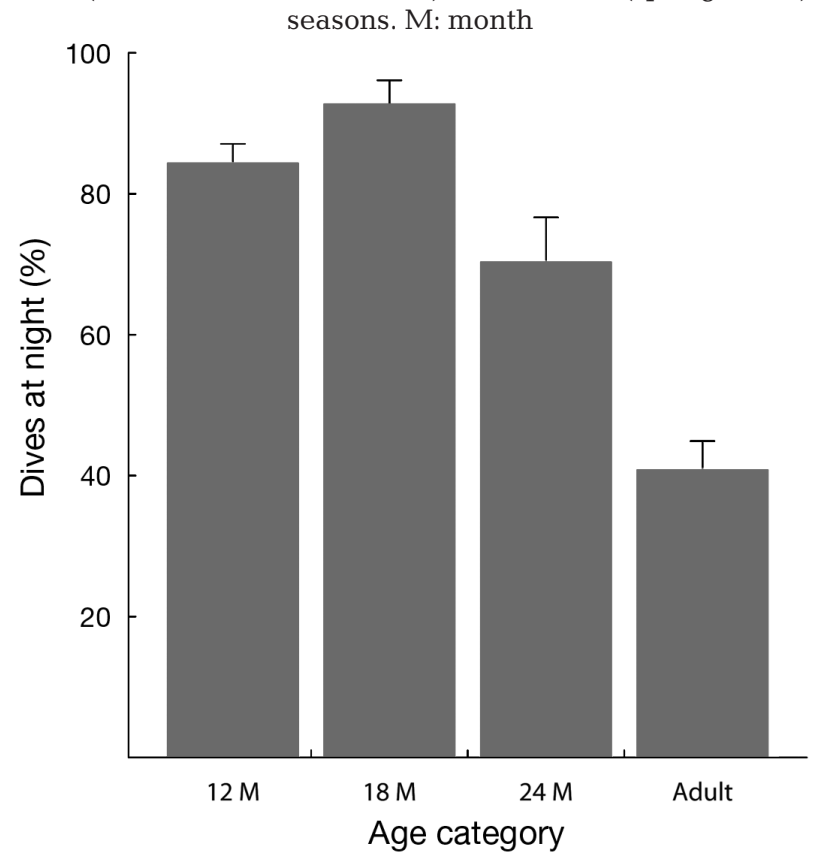

Fig. 3. Zalophus wollebaeki. Percentage of dives performed at night (mean $\pm \mathrm{SE}$ ) for diving Galapagos sea lion age categories sampled in the regular cold (autumn 2008 and 2009) and warm (spring 2009) seasons. M: month

veniles (LME, $t=2.588, \mathrm{p}=0.02$, Table 2 ). The change of PC1 of $24 \mathrm{M}$ juveniles was substantial, representing approximately $18 \%$ of the range of $\mathrm{PC} 1$ values (range, -3.5 to 7.95 ; LME estimated increase of PC1 in $24 \mathrm{M}$



Fig. 4. Zalophus wollebaeki. Percentage of time spent at the bottom of dives (mean $\pm \mathrm{SE}$ ) for all diving Galapagos sea lion age categories sampled in the regular seasons (black bars) and the El Niño season (grey bars). M: month

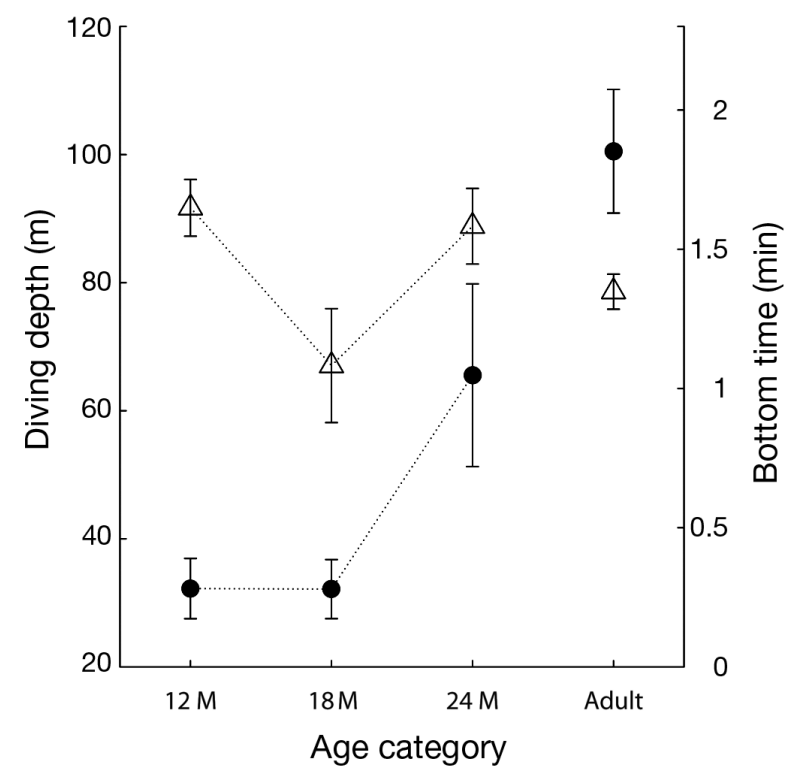

Fig. 5. Zalophus wollebaeki. Diving depth and bottom time (mean $\pm \mathrm{SE}$ ) for all diving Galapagos sea lion age categories sampled in the regular cold and warm seasons. Circles signify diving depth ( $y$-axis on the left) and triangles signify bottom time ( $y$-axis on the right). M: month

juveniles, $1.72 \pm 0.49$ ). Body mass was significantly positively related to $\mathrm{PC} 1$ for all 3 juvenile age classes (LME, mass: $t=3.77, \mathrm{p}<0.01$ ), e.g. maximum dive duration increased with body mass (Fig. 6). 
Table 4. Zalophus wollebaeki. Linear mixed-effect model selection results for dive behaviour of juvenile Galapagos sea lion (GSL) divers using 3 principal components as response variables. Models related different aspects of the diving behaviour (see Table 3 for loadings, and 'Results' and 'Discussion' for component interpretation) of juvenile GSL to age category, sex and body mass. Values are the number of parameters in the model $(k)$, Akaike's information criterion corrected for small sample sizes $\left(\mathrm{AIC}_{\mathrm{c}}\right)$, the difference between model $\mathrm{AIC}_{\mathrm{C}} \mathrm{s}$ and minimum (best model) $\mathrm{AIC}_{\mathrm{C}}\left(\Delta \mathrm{AIC}_{\mathrm{C}}\right)$ and the Akaike weights $\left(\mathrm{wAIC}_{\mathrm{c}}\right)$. Models are ranked in the order of their corrected Akaike weights

\begin{tabular}{|lcccc|}
\hline Model & $k$ & $\mathrm{AIC}_{\mathrm{C}}$ & $\Delta \mathrm{AIC}_{\mathrm{c}}$ & $\mathrm{wAIC}_{\mathrm{c}}$ \\
\hline PC1 related to: & & & & \\
Age + Mass & 6 & 197.2 & 0.000 & 0.546 \\
Age + Mass + Sex & 7 & 198.6 & 0.801 & 0.364 \\
PC2 related to: & & & & \\
Age & 5 & 171.1 & 0.000 & 0.533 \\
Age + Sex & 6 & 172.4 & 1.308 & 0.277 \\
PC3 related to: & & & & \\
Age & 5 & 153.2 & 0.000 & 0.560 \\
Age + Sex & 6 & 153.9 & 0.946 & 0.349 \\
\hline
\end{tabular}

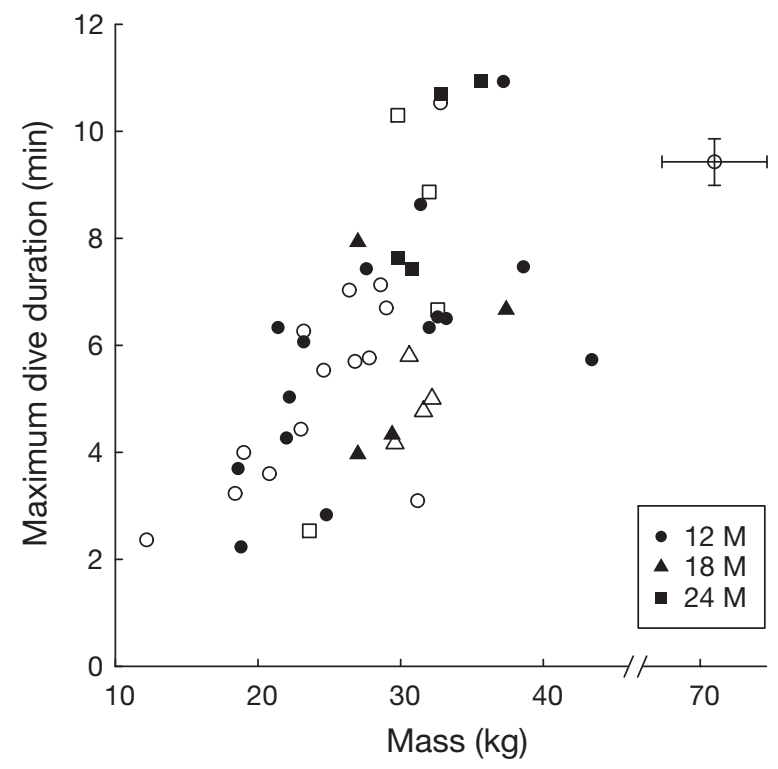

Fig. 6. Zalophus wollebaeki. Relationship of maximum dive duration and body mass for 12M, 18M and 24M Galapagos sea lions juveniles sampled in the regular cold (autumn 2008 and 2009) and warm (spring 2009) seasons. Sex is indicated by filled (female) and open (male) symbols. Adult female mass and maximum dive duration are indicated in the upper right as mean \pm SE. M: month

The second principal component (PC2) was correlated with dive duration, bottom time and proportion of dive duration spend at the bottom (TAB). These aspects of dive behaviour were best described by a model that used only age as the explanatory variable.
Sex had little influence as the second best model, Age + Sex, fitted the data only half as well as the best model $\left(\mathrm{wAIC}_{\mathrm{c}}=0.256\right.$, Table 4). PC2 differed significantly between $12 \mathrm{M}$ and $18 \mathrm{M}$ juveniles (LME, $t=$ $3.489, \mathrm{p}<0.01)$ but, somewhat surprisingly, not between $12 \mathrm{M}$ and $24 \mathrm{M}$ juveniles (LME, $t=0.595, \mathrm{p}>$ 0.05).

The change of PC2 in $18 \mathrm{M}$ juveniles was substantial, representing approximately $23 \%$ of the range of PC2 values (range, -3.87 to 3.71 ; LME estimate $1.72 \pm 0.49$ ). The decrease in bottom time and TAB in $18 \mathrm{M}$ juveniles in comparison with older and younger juvenile age classes are illustrated in Figs. $4 \& 5$.

The third principal component (PC3) reflected mainly TSD and dive rate. Again, a model with age as the only explanatory variable fitted better than the second best model, Age + Sex $\left(\mathrm{wAIC}_{\mathrm{c}}=0.211\right.$, Table 4). PC3 for 12M and 18M juveniles was similar (LME, $t=-0.942, \mathrm{p}>0.05$ ), but differed between $12 \mathrm{M}$ and $24 \mathrm{M}$ juveniles (LME, $t=-2.646, \mathrm{p}=0.02$ ). Again, PC3 changed substantially in $24 \mathrm{M}$ juveniles, representing approximately $21 \%$ of the range of PC3 values (range, -2.11 to 3.2 ; LME estimate, $1.1 \pm 0.43$ ).

\section{Onset of independent foraging}

We investigated stable isotope signatures to obtain an indication for the onset of independent foraging, as a dietary shift from maternal milk to marine organisms is expected to result in a decrease in stable nitrogen isotope ratios in the tissue of juveniles. Stable nitrogen isotope signatures differed significantly between age classes (LME, $F_{4,17}=9.880, \mathrm{p}<0.01$ ). $6 \mathrm{M}$ and $12 \mathrm{M}$ juveniles had higher $\delta^{15} \mathrm{~N}$ values than did adult females. Stable nitrogen isotope ratios were enriched by $1.7 \pm 0.45 \%$ for $6 \mathrm{M}$ (LME, $t=3.870$, p < 0.01 , Fig. 7) and $1.1 \pm 0.35 \%$ for $12 \mathrm{M}$ juveniles compared with adult female values (LME, $t=3.029, \mathrm{p}<$ 0.01 , Fig. 7 ). $\delta^{15} \mathrm{~N}$ decreased by $1.5 \%$ between $12 \mathrm{M}$ and $18 \mathrm{M}$ sea lions indicating a dietary shift in juveniles older than $1 \mathrm{yr}$. This decrease was substantial and represented $33 \%$ of the range of $\delta^{15} \mathrm{~N}$ values (range: 11.18 to 15.75). Thereafter, no further change was observed as stable nitrogen ratios of $18 \mathrm{M}$ and $24 \mathrm{M}$ juveniles did not differ significantly from values for adult female (LME, 18M: $t=-1.281, \mathrm{p}=0.218$; $24 \mathrm{M}: t=-0.940, \mathrm{p}=0.360$, Fig. 7). The stable nitrogen isotope signature of juvenile divers was negatively correlated with PC1, measuring foraging effort (Pearson's $\mathrm{r}=-0.424, \mathrm{p}<0.01$ ), but not with $\mathrm{PC} 2$ or PC3 (PC2: Pearson's $r=-0.013, p=0.936 ;$ PC3: Pearson's $r=0.094, p=0.544)$. In contrast to the age-related 


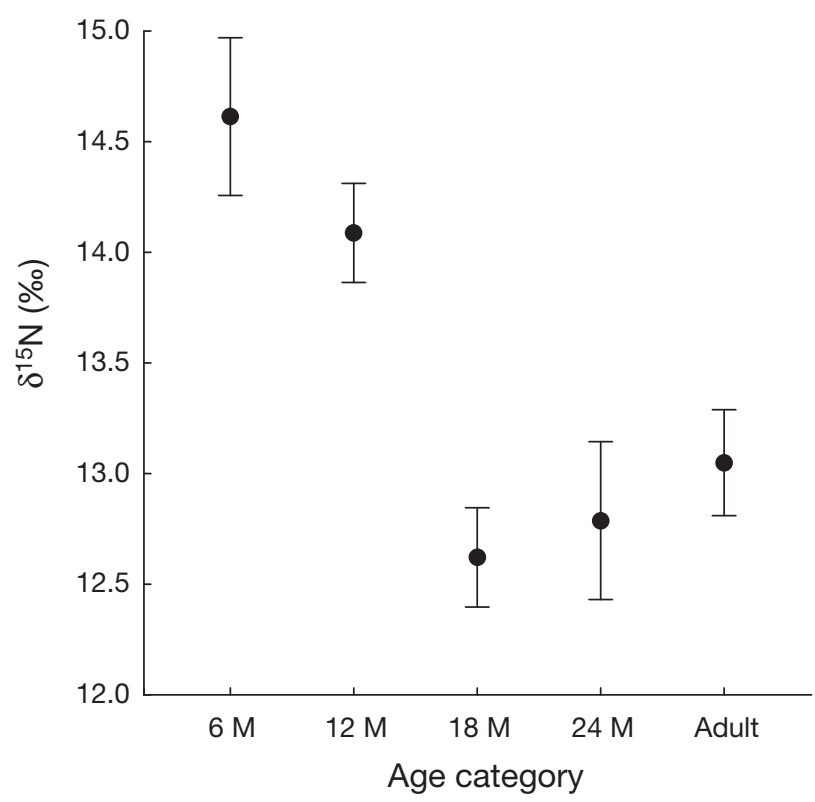

Fig. 7. Zalophus wollebaeki. Stable nitrogen ratios (mean \pm $\mathrm{SE}$ ) for juvenile and adult Galapagos sea lion age categories sampled in regular cold (autumn 2008 and 2009) and warm (spring 2009) seasons demonstrating the strong decline in milk dependency of $18 \mathrm{M}$ juveniles. M: month

decrease in $\delta^{15} \mathrm{~N}$, age had no significant effect on the $\delta^{13} \mathrm{C}$ signature $(-16.2 \pm 0.2,-16.4 \pm 0.1,-16.7 \pm 0.2$, $-16.0 \pm 0.1$ and $-16.3 \pm 0.5 \%$ for $6 \mathrm{M}, 12 \mathrm{M}, 18 \mathrm{M}, 24 \mathrm{M}$ and adult females, respectively; LME, $F_{4,17}=3.03, \mathrm{p}=$ 0.05 , Table 1).

\section{Impact of environmental change on foraging behaviour of juvenile and adult females}

We further investigated the effect of adverse environmental conditions during an El Niño year on foraging behaviour of GSL of different ages. Adult females and $18 \mathrm{M}$ juveniles sampled in the regular and the El Niño warm season, respectively, did not differ in body mass ( $t$-test, adult females: $t=0.694$, $\mathrm{p}=0.503 ; 18 \mathrm{M}: t=-0.220, \mathrm{p}=0.830$; Table 1$)$. However, adult female diving behaviour differed significantly between years (ANOSIM, global R $=0.634, p=$ 0.02). In the El Niño season (April 2010), adult females reduced their dive rate and dived longer and deeper, almost doubling their mean diving depth during the day (Table 2). Consequently, they had shorter bottom times and lower proportions of TAB (Table 2, Fig. 4). Moreover, females increased their average trip duration in the El Niño warm season (Table 2). In contrast, the diving behaviour of $18 \mathrm{M}$ juveniles was similar in April 2009 and 2010 (ANOSIM, global $\mathrm{R}=0.155, \mathrm{p}=0.114$ ). However, some aspects of their diving behaviour differed; during El Niño, 18M individuals spent more time at the bottom of dives ( $t$-test, $t=-3.330, \mathrm{p}<0.01$ ), average dive duration was longer ( $t$-test, $t=-2.390, \mathrm{p}=0.036$, Table 2) and TAB was significantly higher ( $t$-test, $t=$ -2.349 , p < 0.039, Fig. 4).

The $\delta^{15} \mathrm{~N}$ signature of adult GSL females did not differ between the regular and the El Niño warm season ( $t$-test, $\mathrm{p}>0.05$, Fig. 8). In contrast, $\delta^{15} \mathrm{~N}$ values of $18 \mathrm{M}$ juveniles were significantly enriched by $1 \%$ in the exceptionally warm season ( $t$-test, $t=-2.666, \mathrm{p}=$ 0.024 , Fig. 8). Both age classes had enriched $\delta^{13} \mathrm{C}$ signatures in the El Niño season $(18 \mathrm{M}:-16.7 \pm 0.1$ and $-15.6 \pm 0.5 \%$ for regular warm and El Niño seasons, respectively, $t$-test, $t=-2.414, \mathrm{p}=0.034$; adult females: $-16.0 \pm 0.1$ and $-15.5 \pm 0.2 \%$ for regular warm and El Niño seasons, $t=-2.663, \mathrm{p}=0.024$ ).

\section{DISCUSSION}

This study has shown that age and body mass are important factors in the development of the foraging behaviour of an endangered otariid species and has highlighted the effect of environmental change on the time course to independence by combining 2

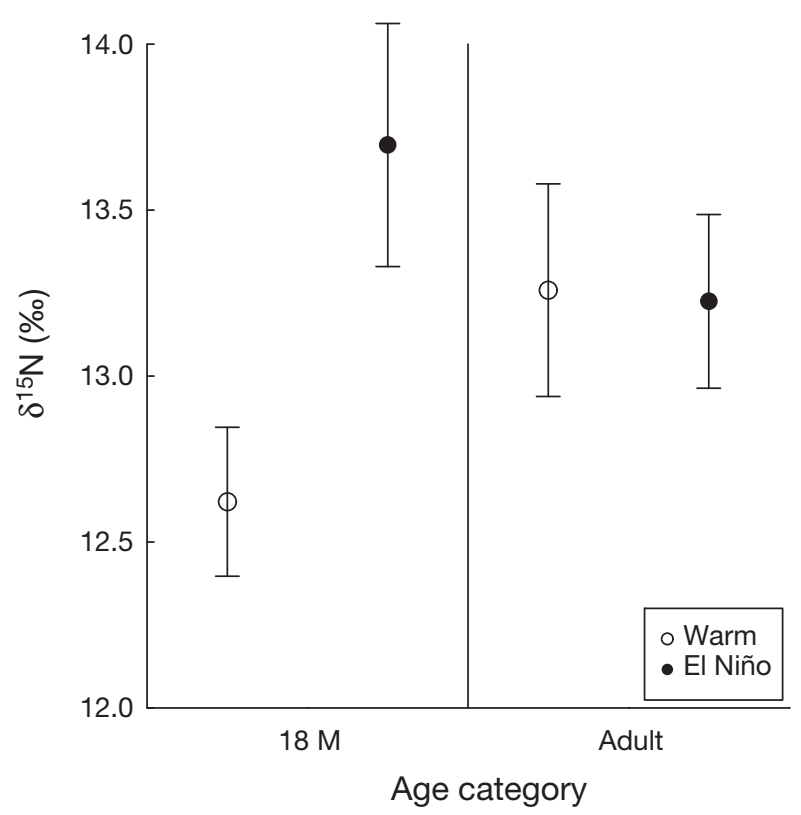

Fig. 8. Zalophus wollebaeki. Stable nitrogen ratios (mean \pm $\mathrm{SE}$ ) for $18 \mathrm{M}$ juveniles and adult Galapagos sea lion females sampled in the regular warm (spring 2009) and El Niño warm (spring 2010) seasons demonstrating the increased $\delta^{15} \mathrm{~N}$ value in $18 \mathrm{M}$ juveniles in the El Niño warm season. M: month 
innovative and complementary methodologies that have not been joined in this context before.

\section{Late onset and development of diving results from slow development}

Juvenile GSL start diving quite late: at 6 mo of age they were essentially surface swimmers and substantial diving activity commenced only at approximately 12 mo of age. This is probably a result of slow physiological development. The ability to dive requires specific physiological adaptations to store and effectively use oxygen. In otariids, the size of oxygen stores and their partitioning (as in adult otariids: 16\% lung, $43 \%$ muscle and $41 \%$ blood; Kooyman \& Ponganis 1998) develop gradually during the postnatal maturation and growth process (Horning \& Trillmich 1997a, Richmond et al. 2006, Spence-Bailey et al. 2007, Weise \& Costa 2007, Trillmich et al. 2008, Verrier et al. 2011). Juvenile otariids develop increased blood oxygen stores first and largely rely on those and on oxygen stored in the lungs when they begin to dive (Burns et al. 2005, Richmond et al. 2006, Weise \& Costa 2007). In the GSL, haematocrit values reach those of adult females only at approximately 12 mo of age (Trillmich et al. 2008). This developmental pace is among the slowest in the otariids (Horning \& Trillmich 1997a, Richmond et al. 2006, Fowler et al. 2007b, Spence-Bailey et al. 2007, Weise \& Costa 2007). Despite this slow rate, haematocrit values of $12 \mathrm{M}$ GSL are higher than reported for same-aged otariids of other species (Horning \& Trillmich 1997a, Richmond et al. 2005). This can help explain the extreme maximum depth and durations of dives that GSL juveniles in this study reached, which agrees with the physiological adaption to deep diving reported for adult females (Villegas-Amtmann \& Costa 2010).

Adult divers, especially in deep diving species, rely to a large extent on muscle oxygen stores (Kooyman \& Ponganis 1998), which develop at a slower rate than blood oxygen stores in juvenile pinnipeds (Burns et al. 2005, Richmond et al. 2006, Fowler et al. 2007b, Weise \& Costa 2007). Juvenile Australian sea lions Neophoca cinerea (ASL) that develop diving abilities at a similar speed as GSL juveniles also develop muscle oxygen stores at a slow rate, and their myoglobin values and diving performance do not reach those of adult females by 24 mo (Fowler et al. 2006, 2007b). No data are available on GSL juvenile muscle oxygen stores, but a similar development is likely given the slow growth of GSL juveniles (Mueller et al. 2011). Addi- tionally, myoglobin values of adult GSL females are among the highest reported for diving vertebrates (Villegas-Amtmann \& Costa 2010) and far exceed those of other otariid species (Richmond et al. 2006, Fowler et al. 2007b, Weise \& Costa 2007), and adult females were found to dive very deep routinely (Villegas-Amtmann et al. 2008, Villegas-Amtmann \& Costa 2010, the present study). In support of this argument, even sea lions from the oldest juvenile age category sampled in our study (24M juveniles) performed at only approximately $70 \%$ of the average and maximum performances of that for adult females in terms of diving depth, duration, trip duration and VTD. These differences are probably caused by ongoing physiological development and smaller juvenile body size. Body mass was an important predictor of increasing juvenile diving depth and duration (PC1, Fig. 6), which agrees with other studies that demonstrate a positive correlation for body size and diving performance in diving mammals and birds (Kooyman 1989, Horning \& Trillmich 1997b, Schreer et al. 2001, Weise et al. 2010). This suggests that the late onset and long drawn-out ontogeny of the GSL is the result of slow growth, similarly slow development of physiological diving abilities and high final (i.e. adult) physiological diving ability.

\section{Ontogenetic niche shift}

Surprisingly, juvenile GSL divers spent similar or even longer times at the bottom than did adult females. Juvenile marine mammals swim and accelerate slower than adults (Schmidt-Nielsen 1972, Horning \& Trillmich 1997b, Noren et al. 2006) and pay higher energetic costs because of their higher mass-specific metabolic rate during diving (SchmidtNielsen 1984, Sparling 2004). Studies in birds have shown that juvenile foragers compensate for their poor foraging efficiency with increased foraging time (Weathers \& Sullivan 1989, Daunt et al. 2007). The long times that juvenile GSL spend at the bottom of dives (Fig. 4) are therefore probably a consequence of their limited foraging efficiency. Given the limited oxygen storage capacities and relatively higher costs of locomotion, extending bottom time is only possible by diving to much shallower depths (Fig. 5). A similar trade-off in favour of increased foraging time was found in ASL juveniles (Fowler et al. 2006). Juvenile GSL appear, therefore, restricted to a limited range of depths at which they can efficiently exploit prey. Constraints to their vertical distribution, in turn, affect which type of prey can be targeted and when. 
Galapagos fur seals Arctocephalus galapagoensis for example, that are similar in size to juvenile GSL, dive exclusively at night and exploit vertically migrating prey of the deep scattering layer that rise to the surface at night but appear inaccessible during moonlit nights and daytime (Horning \& Trillmich 1997b, 1999). As a likely consequence of similar size-related constraints, juvenile GSL employed a diving pattern that differed from adult female behaviour by much shallower depths, an almost 2-fold increase in dive rate and a high concentration of diving activity at night. This contrasts interestingly with other otariid species, in which different age classes employ the same foraging strategy and diurnal pattern, e.g. nocturnal, epipelagic foraging or benthic foraging (Horning \& Trillmich 1997b, Baylis et al. 2005, Fowler et al. 2006, Spence-Bailey et al. 2007). Information on the spatial distribution of foraging locations of the different age categories in relation to water depths would clarify whether GSL juveniles indeed employ a differing strategy, e.g. epipelagic diving contrasting with a mixture of epipelagic and benthic diving in adult females (Villegas-Amtmann et al. 2008). Juvenile GSL diving behaviour resembles the 'shallow diver strategy' that has been described by looking at individual adult GSL diving behaviour (Villegas-Amtmann et al. 2008). It appears that these strategies allow adjustments to variable prey distribution and stage-specific physiological limitations and reflect behavioural flexibility of a species confronted with an unpredictable environment with patchy prey distribution. Such ontogenetic niche shifts and their implications have been studied in depth in invertebrates, fish, reptiles and some mammal species (Werner \& Gilliam 1984, Adams 1996, Estrada et al. 2006, Subalusky et al. 2009) but have received less attention in mammals, specifically in pinnipeds (but see Frid et al. 2009). The differences in juvenile and adult GSL foraging strategies found in the GSL suggest that age-specific constraints and consequent foraging adaptations should be taken into consideration when interpreting and modelling foraging habitat choice and ecological interactions between species, and formulating conservation strategies.

\section{Delayed development of independent foraging and age dependent changes in foraging strategy}

Stable nitrogen isotope signatures of juvenile GSL decreased from an initial enriched trophic position throughout their ontogeny while $\delta^{13} \mathrm{C}$ did not significantly change. These findings are similar to the patterns of ontogenetic changes in stable isotope signatures of other mammal species (Balasse 2001, Newsome et al. 2006, Dalerum et al. 2007, York et al. 2008). The enrichment of $1.7 \%$ in $\delta^{15} \mathrm{~N}$ signatures of $6 \mathrm{M}$ GSL juveniles is similar to published measured or assumed fractionation between pinniped mothers and fully dependent offspring (Aurioles-Gamboa et al. 2009, Habran et al. 2010, Lowther \& Goldsworthy 2011 ), indicating that $6 \mathrm{M}$ juveniles completely relied on maternal milk. Somewhat surprisingly, $12 \mathrm{M}$ juveniles showed similarly enriched $\delta^{15} \mathrm{~N}$ values despite substantial diving ability, i.e. the longest time diving (TSD) of all juvenile age classes, long bottom times and the largest proportion of TAB. This combination suggests that $12 \mathrm{M}$ juveniles exerted a high effort but had little success, which led to an ongoing nutritional dependency on maternal milk. The depleted stable nitrogen signatures of $18 \mathrm{M}$ juveniles indicate a decrease in the contribution of maternal milk and an increase in self-acquired nutrition. In line with this, Mueller et al. (2011) reported a decrease in the observed frequency of suckling events in this cohort in comparison to younger age classes. This transition is probably caused by increasing foraging skills and physiological development, which increase energetic demands that possibly interact with a decreasing availability of maternal milk. Heinsohn (1991) suggested that patchily distributed food resources require an extended learning time to acquire complex foraging skills, which might explain the considerable amount of time that GSL juveniles appear to forage unsuccessfully. To date, no similar study in otariid species distributed in different habitats is available, but it would be highly informative to investigate ecological factors influencing juvenile development to nutritional independence.

It is not clear from our results whether $18 \mathrm{M}$ and $24 \mathrm{M}$ juveniles are nutritionally independent. Foraging juvenile pinnipeds often target prey of differing size and trophic position than do adult animals (Page \& McKenzie 2005, Field et al. 2007), which would lead to differences in stable nitrogen signature (Kelly 2000, Newsome et al. 2010). However, 18M and 24M juvenile $\delta^{15} \mathrm{~N}$ values did not differ from those of adult females in our study, which is similar to what has been found in California sea lions Zalophus californianus (Newsome et al. 2006). Given the apparent necessity to perform deep, energetically costly dives, as adult GSL females do, it seems unlikely that their type of prey is available at shallower depths that are accessible and exploitable by GSL juveniles. We therefore interpret the similar $\delta^{15} \mathrm{~N}$ of $18 \mathrm{M}, 24 \mathrm{M}$ and adult females as a signal that juvenile GSL partially 
depend on maternal milk and supplement their energy budget up to an age of at least 2 yr. This is supported by occasional facultative nursing observations in these older age classes (Mueller et al. 2011, J. W. E. Jeglinski unpubl. data).

The diving performance of juvenile GSL shows a clear ontogenetic trend and increases with age (PC1, PC2). Unsurprisingly, the negative relationship between PC1 and $\delta^{15} \mathrm{~N}$ values indicates that better performing juveniles had higher foraging success and contributed more to their energy budget by independent foraging. However, the seasonality of the productivity in the Galapagos marine ecosystem coupled with the energetic costs of increasingly independent foraging adds complexity to the interpretation of juvenile diving behaviour. Aspects of the diving behaviour of $18 \mathrm{M}$ juveniles indicate a specific foraging pattern that might be an adaptation to changes in prey distribution and abundance; dive duration and bottom times (PC2) of 18M juveniles were shorter than that of $12 \mathrm{M}$ and $24 \mathrm{M}$ juveniles, while night activity and dive rate were increased. Additionally, 18M juveniles exhibited the highest dive effort ( $>10 \mathrm{~km} \mathrm{~d}^{-1}$ travelled vertically) suggesting that $18 \mathrm{M}$ juveniles are highly constrained in coping with the increasing need to forage successfully during environmentally unfavourable conditions. At this crucial stage, juvenile foragers seem to be most vulnerable and individual differences in growth or development of foraging skills may determine foraging success and ultimately survival.

\section{Influence of marine conditions on foraging behav- iour of juvenile and adult GSL}

During the El Niño warm season adult GSL females changed aspects of their diving behaviour according to deteriorating marine conditions by diving deeper and longer, extending trips and diving predominately during the day. Similar adjustments were found in other otariid species comparing years with higher and lower productivity (McCafferty et al. 1998, Georges et al. 2000, Costa 2008, Melin et al. 2008). Studies off the coasts of Peru and Chile suggest that fish species groups like sardines, anchovies and silversides either migrated to other locations or withdrew to deeper depths in El Niño conditions (Arntz et al. 1991). Similar changes in spatial distribution of prey may occur in the Galapagos. The stable nitrogen signature of adult females did not change, which indicates that adult females continued feeding on a similar type and mixture of prey items, but adjusted their vertical foraging space to find them. Given the limited range of diving depth effectively exploitable by juvenile GSL, these adjustments did not seem possible. Contrasting with adult behaviour, $18 \mathrm{M}$ juveniles performed longer dives, spent more time at the bottom of a dive, had a significantly increased proportion of time at the bottom and allocated a high proportion of time to diving, but had enriched $\delta^{15} \mathrm{~N}$ signatures (Figs. $4 \& 8$ ). Thus, the foraging behaviour of 18M GSL juveniles in the El Niño warm season resembled the intensive but ineffective foraging trials of $12 \mathrm{M}$ juveniles.

An increase in stable nitrogen ratios as a result of starving or fasting (Hobson et al. 1993, Cherel et al. 2005, Fuller et al. 2005) seems unlikely, because neither body mass nor length of 18M juveniles differed between the regular and the El Niño warm seasons. Also, the increased diving activity shown by this age class contradicts the decrease in activity that would be expected owing to energetic restrictions during fasting (Verrier et al. 2011). Furthermore, fasting animals have been shown to have depleted $\delta^{13} \mathrm{C}$ signatures (Cherel et al. 2005), but stable carbon signatures of adult female and juveniles increased in our study. We therefore suggest that the enriched stable nitrogen signatures of $18 \mathrm{M}$ juveniles indicate a delay in the onset of successful independent foraging owing to decreased food abundance during El Niño conditions, while enriched stable carbon signatures of both adult females and 18M juveniles probably resulted from changes in upwelling and in the underlying ecosystem carbon signature.

Strong El Niño events result in an increase in SST of about $8^{\circ} \mathrm{C}$ (Duffy \& Merlen 1986) and have deleterious effects for juveniles resulting in an almost complete loss of all juvenile cohorts up to $2 \mathrm{yr}$ (Trillmich \& Limberger 1985, Trillmich \& Dellinger 1991). The El Niño event in spring 2010 caused only a relatively slight increase of SST of about $2{ }^{\circ} \mathrm{C}$ and was classified as mild (NOAA 2010). Our data show that even a mild event appears to influence the pace of the development to independence of juveniles and may have a feedback effect on adult female reproduction.

\section{Implications for female reproduction}

The slow development of diving abilities in GSL juveniles requires high and continuous maternal investment in offspring far beyond the first year. GSL females pup on average every 2 to $3 \mathrm{yr}$ (B. Mueller unpubl. data), which indicates that it is rarely energetically possible to meet the demands of a suckling 
juvenile, a growing fetus and self-maintenance simultaneously. By missing out on one or several reproductive cycles, females increase the survival chances of the existing offspring at the cost of a reduced reproductive rate. In an average year, the female's need to reallocate energy to the developing fetus as well as increased maintenance costs due to warm season conditions may contribute to induce an increased foraging effort in $18 \mathrm{M}$ juveniles. Under El Niño conditions females seem to decide this tradeoff in favour of their existing offspring. This indicates how closely juvenile survival is tied to marine food abundance and how necessary maternal energy input is to buffer juvenile development against the unpredictability of the environment. Limited data on the life history strategy of GSL females indicate adaptations to high environmental stochasticity such as late onset of first breeding and low reproductive rate (B. Mueller \& F. Trillmich unpubl. data) that have been suggested to be optimal under such conditions (Benton et al. 1995, Lindström 1999). Our results suggest a functional link between the inabilities of juveniles to cope independently with poor environmental conditions resulting in an increased maternal investment, which probably leads to a reduced reproductive rate. The direct feedback of unfavourable environmental conditions on the speed of juvenile development, the connection to prolonged high maternal investment and its demographic implications emphasises an aspect of vulnerability of an endangered species that has to date received little attention. We strongly encourage similar studies combining juvenile foraging success and maternal investment covering several years of varying environmental conditions. Our findings provide an important starting point for such studies and may offer valuable insights into the response of marine apex predators to increasing environmental variability on the background of a changing climate (Simmonds \& Isaac 2007).

Acknowledgements. The present study was performed under permit nos. PC-11-08 and PC-043-09 of the National Park Service, Galapagos, and was financed by the German Science Foundation (DFG grant no. TR 105/19-1) and the National Geographic Society (grant no. 8682-09). We received highly appreciated material sponsorship by Panasonic, Ortlieb, Zarges and Huntsmann Advanced Materials. The Charles Darwin Research Station provided logistic support during field work. We thank B. Mueller, V. FrancoTrecu, D. Anchundia, M. Meija, K. Meise, M. Marquard, E. Garcia Bartholomei, S. Maxwell, G. McDonald and M. Tift for their help in the field. B. Teichner and E. Hippauf helped invaluably with lab work. P. Brock and 3 anonymous reviewers provided valuable comments to this manuscript.

\section{LITERATURE CITED}

Adams RA (1996) Size-specific resource use in juvenile little brown bats, Myotis lucifugus (Chiroptera: Vespertilionidae): Is there an ontogenetic shift? Can J Zool 74: 1204-1210

Anderson DJ (1989) Differential responses of boobies and other seabirds in the Galapagos to the 1986-87 El NiñoSouthern Oscillation event. Mar Ecol Prog Ser 52: 209-216

Arntz W, Pearcy WG, Trillmich F (1991) Biological consequences of the 1982-83 El Niño in the Eastern Pacific. In: Trillmich F, Ono KA (eds) Pinnipeds and El Niño. Springer Verlag, Berlin, p 22-42

Aurioles-Gamboa D, Newsome SD, Salazar-Pico S, Koch PL (2009) Stable isotope differences between sea lions (Zalophus) from the Gulf of California and Galápagos Islands. J Mammal 90:1410-1420

Balasse M (2001) Detection of dietary changes by intra-tooth carbon and nitrogen isotopic analysis: an experimental study of dentine collagen of cattle (Bos taurus). J Archaeol Sci 28:235-245

Barber RT, Chavez FP (1983) Biological consequences of El Niño. Science 222:1203-1210

- Baylis AMM, Page B, Peters K, McIntosh R, McKenzie J, Goldsworthy S (2005) The ontogeny of diving behaviour in New Zealand fur seal pups (Arctocephalus forsteri). Can J Zool 83:1149-1161

Benton TG, Grant A, Clutton-Brock TH (1995) Does environmental stochasticity matter? Analysis of red deer lifehistories on Rum. Evol Ecol 9:559-574

Brito JC (2004) Feeding ecology of Vipera la tastei in northern Portugal: ontogenetic shifts, prey size and seasonal variations. Herpetol J 14:13-19

Burnham KP, Anderson DR (2002) Model selection and multi model inference: a practical information-theoretical approach, 2nd edn. Springer, New York, NY

> Burns JM, Clark CA, Richmond JP (2004) The impact of lactation strategy on physiological development of juvenile marine mammals: implications for the transition to independent foraging. Int Congr Ser 1275:341-350

> Burns JM, Frost K, Harvey JT (2005) Development of body oxygen stores in harbor seals: effects of age, mass, and body composition. Physiol Biochem Zool 78: 1057-1068

Cherel Y, Hobson KA, Bailleul F, Groscolas R (2005) Nutrition, physiology, and stable isotopes: new information from fasting and molting penguins. Ecology 86: 2881-2888

Costa DP (1991) Reproductive and foraging energetics of high latitude penguins, albatrosses and pinnipeds: implications for life history patterns. Am Zool 130:111-130

Costa DP (2008) A conceptual model of the variation in parental attendance in response to environmental fluctuation: foraging energetics of lactating sea lions and fur seals. Ecology 52:44-52

Craig MP, Ragen TJ (1999) Body size, survival, and decline of juvenile Hawaiian monk seals, Monachus schauinslandi. Mar Mamm Sci 15:786-809

> Dalerum F, Bennett NC, Clutton-Brock TH (2007) Longitudinal differences in ${ }^{15} \mathrm{~N}$ between mothers and offspring during and after weaning in a small cooperative mammal, the meerkat (Suricata suricatta). Rapid Commun Mass Spectrom 21:1889-1892

> Daunt F, Afanasyev V, Adam A, Croxall JP, Wanless S (2007) 
From cradle to early grave: juvenile mortality in European shags Phalacrocorax aristotelis results from inadequate development of foraging proficiency. Biol Lett 3: 371-374

> DeNiro M, Epstein S (1981) Influence of diet on the distribution of nitrogen isotopes in animals. Geochim Cosmochim Acta 45:341-351

> Dobush GR, Ankney CD, Krementz DG (1985) The effect of apparatus, extraction time, and solvent type on lipid extractions of snow geese. Can J Zool 63:1917-1920

Doidge DW, Croxall JP (1989) Factors affecting weaning weight in Antarctic fur seals Arctocephalus gazella at South Georgia. Polar Biol 9:155-160

> Donohue MJ, Costa DP, Goebel ME, Baker JD (2000) The ontogeny of metabolic rate and thermoregulatory capabilities of northern fur seal, Callorhinus ursinus, pups in air and water. J Exp Biol 203:1003-1016

> Duchamp C, Rouanet JL, Barré H (2002) Ontogeny of thermoregulatory mechanisms in king penguin chicks (Aptenodytes patagonicus). Comp Biochem Physiol A 131:765-773

Duffy DC, Merlen G (1986) Seabird densities and aggregations during the 1983 El Niño in the Galapagos Islands. Wilson Bull 98:588-591

- Estrada JA, Rice AN, Natanson LJ, Skomal GB (2006) Use of isotopic analysis of vertebrae in reconstructing ontogenetic feeding ecology in white sharks. Ecology 87: 829-834

Feldman G, Clark D, Halpern D (1984) Satellite color observations of the phytoplankton distribution in the eastern Equatorial Pacific during the 1982-1983 El Niño. Science 226:1069-1071

> Fiedler PC (1994) Seasonal and environmental variability of coastal zone color scanner phytoplankton pigments and winds in the eastern tropical Pacific. J Geophys Res 99: 18,371-18, 384

Field IC, Bradshaw CJA, van den Hoff J, Burton HR, Hindell MA (2007) Age-related shifts in the diet composition of southern elephant seals expand overall foraging niche. Mar Biol 150:1441-1452

- Fowler SL, Costa DP, Arnould JPY, Gales NJ, Kuhn CE (2006) Ontogeny of diving behaviour in the Australian sea lion: trials of adolescence in a late bloomer. J Anim Ecol 75:358-367

Fowler SL, Costa DP, Arnould JPY (2007a) Ontogeny of movements and foraging ranges in the Australian sea lion. Mar Mamm Sci 23:598-614

Fowler SL, Costa DP, Arnould JPY, Gales NJ, Burns JM (2007b) Ontogeny of oxygen stores and physiological diving capability in Australian sea lions. Funct Ecol 21: 922-935

Frid A, Burns J, Baker GG, Thorne RE (2009) Predicting synergistic effects of resources and predators on foraging decisions by juvenile Steller sea lions. Oecologia 158: 775-786

- Fuller BT, Fuller JL, Sage NE, Harris DA, O'Connell TC, Hedges REM (2005) Nitrogen balance and $\delta^{15} \mathrm{~N}$ : Why you're not what you eat during nutritional stress. Rapid Commun Mass Spectrom 19:2497-2506

Fuller BT, Fuller JL, Harris DA, Hedges REM (2006) Detection of breastfeeding and weaning in modern human infants with carbon and nitrogen stable isotope ratios. Am J Phys Anthropol 129:279-293

Geist DJ, Fornari DJ, Kurz MD, Harpp KS, Adam Soule S, Perfit MR, Koleszar AM (2006) Submarine Fernandina: magmatism at the leading edge of the Galápagos hot spot. Geochem Geophys Geosyst 7:1-27

> Georges JY, Bonadonna F, Guinet C (2000) Foraging habitat and diving activity of lactating Subantarctic fur seals in relation to sea-surface temperatures at Amsterdam Island. Mar Ecol Prog Ser 196:291-304

> Habran S, Debier C, Crocker DE, Houser DS, Lepoint G, Bouquegneau JM, Das K (2010) Assessment of gestation, lactation and fasting on stable isotope ratios in northern elephant seals (Mirounga angustirostris). Mar Mamm Sci 26:880-895

Heinsohn RG (1991) Slow learning of foraging skills and extended parental care in cooperatively breeding white winged coughs. Am Nat 137:864-881

Hobson KA, Alisauskas RT, Clark RG (1993) Stable-nitrogen isotope enrichment in avian tissues due to fasting and nutritional stress: implications for isotopic analyses of diet. Auk 95:388-394

Hobson KA, Sease JL, Merrick RL, Piatt JF (1997) Investigating trophic relationships of pinnipeds in Alaska and Washington using stable isotope ratios of nitrogen and carbon. Mar Mamm Sci 13:114-132

> Horning M, Trillmich F (1997a) Development of hemoglobin, hematocrit, and erythrocyte values in Galapagos fur seals. Mar Mamm Sci 13:100-113

Horning M, Trillmich F (1997b) The ontogeny of the diving behaviour in the Galapagos fur seal. Behaviour 134: 1211-1257

Horning M, Trillmich F (1999) Lunar cycles in diel prey migrations exert a stronger effect on the diving of juveniles than adult Galápagos fur seals. Proc Biol Sci 266: 1127-1132

Houghton JT, Ding Y, Griggs DJ, Noguer $M$ and others (eds) (2001) Climate change 2001: the scientific basis. Contribution of Working Group I to the Third Assessment Report of the Intergovernmental Panel on Climate Change. Cambridge University Press, Cambridge

Jeglinski JWE, Mueller B, Pörschmann U, Trillmich F (2010) Field-based age estimation of juvenile Galapagos sea lions (Zalophus wollebaeki) using morphometric measurements. Aquat Mamm 36:262-269

Jenkins SG, Partridge ST, Stephenson TR, Farley SD, Robbins CT (2001) Nitrogen and carbon isotope fractionation between mothers, neonates, and nursing offspring. Oecologia 129:336-341

- Kelly JF (2000) Stable isotopes of carbon and nitrogen in the study of avian and mammalian trophic ecology. Can J Zool 78:1-27

Kooyman GL (1989) Diverse divers: physiology and behaviour. Springer, Berlin

Kooyman GL, Ponganis PJ (1998) The physiological basis of diving to depth: birds and mammals. Annu Rev Physiol 60:19-32

> Kurle CM, Worthy GAJ (2002) Stable nitrogen and carbon isotope ratios in multiple tissues of the northern fur seal Callorhinus ursinus: implications for dietary and migratory reconstructions. Mar Ecol Prog Ser 236:289-300

La Croix S, Zelditch ML, Shivik JA, Lundrigan BL, Holekamp KE (2011) Ontogeny of feeding performance and biomechanics in coyotes. J Zool 285:301-315

Lea M, Johnson D, Melin S, Ream R, Gelatt T (2010) Diving ontogeny and lunar responses in a highly migratory mammal, the northern fur seal Callorhinus ursinus. Mar Ecol Prog Ser 419:233-247 
Lindström J (1999) Early development and fitness in birds and mammals. Trends Ecol Evol 14:343-348

> Lowther AD, Goldsworthy SD (2011) Detecting alternate foraging ecotypes in Australian sea lion (Neophoca cinerea) colonies using stable isotope analysis. Mar Mamm Sci 27: 567-586

> McCafferty D, Boyd I, Walker T, Taylor R (1998) Foraging responses of Antarctic fur seals to changes in the marine environment. Mar Ecol Prog Ser 166:285-299

> McMahon CR, Burton HR (2005) Climate change and seal survival: evidence for environmentally mediated changes in elephant seal, Mirounga leonina, pup survival. Proc Biol Sci 272:923-928

Melin SR, DeLong RL, Siniff DB (2008) The effects of El Niño on the foraging behavior of lactating California sea lions (Zalophus californianus californianus) during the nonbreeding season. Can J Zool 86:192-206

- Minagawa M, Wada E (1984) Stepwise enrichment of ${ }^{15} \mathrm{~N}$ along food chains: further evidence and the relation between $\delta^{15} \mathrm{~N}$ and animal age. Geochim Cosmochim Acta 48:1135-1140

> Mueller B, Pörschmann U, Wolf JBW, Trillmich F (2011) Growth under uncertainty: the influence of marine variability on early development of Galapagos sea lions. Mar Mamm Sci 27:350-365

Munn AJ, Dawson TJ (2003) Energy requirements of the red kangaroo (Macropus rufus): impacts of age, growth and body size in a large desert-dwelling herbivore. J Comp Physiol B 173:575-582

Munn AJ, Dawson TJ (2006) Forage fibre digestion, rates of feed passage and gut fill in juvenile and adult red kangaroos Macropus rufus Desmarest: why body size matters. J Exp Biol 209:1535-1547

- Newsome SD, Koch PL, Etnier MA, Aurioles-Gamboa D (2006) Using carbon and nitrogen isotope values to investigate maternal strategies in northeast Pacific otariids. Mar Mamm Sci 22:556-572

Newsome SD, Martinez del Rio C, Bearhop S, Phillips DL (2007) A niche for isotopic ecology. Front Ecol Environ 5: 429-436

Newsome SD, Clementz MT, Koch PL (2010) Using stable isotope biogeochemistry to study marine mammal ecology. Mar Mamm Sci 26:509-572

NOAA (National Oceanic and Atmospheric Administration) (2010) El Niño/Southern Oscillation (ENSO) diagnostic discussion ENSO Status: El Niño Advisory. NOAA Climate Prediction Center, Camp Springs, MD

> Noren SR, Biedenbach G, Edwards EF (2006) Ontogeny of swim performance and mechanics in bottlenose dolphins (Tursiops truncatus). J Exp Biol 209:4724-4731

$>$ Owen-Smith N (1990) Demography of a large herbivore, the greater kudu Tragelaphus strepsiceros, in relation to rainfall. J Anim Ecol 59:893-913

Page B, McKenzie J (2005) Dietary resource partitioning among sympatric New Zealand and Australian fur seals. Mar Ecol Prog Ser 293:283-302

Palacios DM (2004) Seasonal patterns of sea-surface temperature and ocean color around the Galápagos: regional and local influences. Deep-Sea Res II 51: 43-57

> Pörschmann U, Trillmich F, Mueller B, Wolf JBW (2010) Male reproductive success and its behavioural correlates in a polygynous mammal, the Galápagos sea lion (Zalophus wollebaeki). Mol Ecol 19:2574-2586

> Post DM (2002) Using stable isotopes to estimate trophic position: models, methods, and assumptions. Ecology 83: 703-718

R Development Core Team (2010) R: a language and environment for statistical computing. R Foundation for Statistical Computing, Vienna

Richmond JP, Burns JM, Rea LD, Mashburn KL (2005) Postnatal ontogeny of erythropoietin and hematology in freeranging Steller sea lions (Eumetopias jubatus). Gen Comp Endocrinol 141:240-247

Richmond JP, Burns JM, Rea LD (2006) Ontogeny of total body oxygen stores and aerobic dive potential in Steller sea lions (Eumetopias jubatus). J Comp Physiol B 176: $535-545$

Robinson PW, Villegas-Amtmann S, Costa DP (2009) Field validation of an inexpensive time-depth recorder. Mar Mamm Sci 25:199-205

> Schmidt-Nielsen K (1972) Locomotion: energy cost of swimming, flying, and running. Science 177:222-228

Schmidt-Nielsen K (1984) Scaling: Why is animal size so important? Cambridge University Press, Cambridge

Schreer JF, Kovacs KM, O'Hara Hines RJ (2001) Comparative diving patterns of pinnipeds and seabirds. Ecol Monogr 71:137-162

Scott D (1980) Functional aspects of prolonged parental care in Bewick's swans. Anim Behav 28:938-952

Simmonds MP, Isaac SJ (2007) The impacts of climate change on marine mammals: early signs of significant problems. Oryx 41:19-26

Singer FJ, Harting A, Symonds KK, Coughenour MB (1991) Density dependence, compensation, and environmental effects on elk calf mortality in Yellowstone National Park. J Wildl Manag 61:12-25

Sol D, Santos DM, Garcia J, Cuadrado M (1998) Competition for food in urban pidgeons: the costs of being juvenile. Condor 100:298-304

Sparling CE (2004) Metabolic rates of captive grey seals during voluntary diving. J Exp Biol 207:1615-1624

Spence-Bailey LM, Verrier D, Arnould JPY (2007) The physiological and behavioural development of diving in Australian fur seal (Arctocephalus pusillus doriferus) pups. J Comp Physiol B 177:483-494

Subalusky AL, Fitzgerald LA, Smith LL (2009) Ontogenetic niche shifts in the American alligator establish functional connectivity between aquatic systems. Biol Conserv 142: 1507-1514

> Trenberth KE, Hoar TJ (1997) Climate change and El Niño. Geophys Res Lett 24:3057-3060

> Thornton A (2008) Early body condition, time budgets and the acquisition of foraging skills in meerkats. Anim Behav 75:951-962

Trillmich F (1990) The behavioural ecology of maternal effort in fur seals and sea lions. Behaviour 114:3-20

Trillmich F, Dellinger T (1991) The effects of El Niño on Galapagos pinnipeds. In: Trillmich F, Ono KA (eds) Pinnipeds and El Niño. Springer Verlag, Berlin, p 66-74

$>$ Trillmich F, Limberger D (1985) Drastic effects of El Niño on Galapagos pinnipeds. Oecologia 67:19-22

> Trillmich F, Wolf JBW (2007) Parent-offspring and sibling conflict in Galápagos fur seals and sea lions. Behav Ecol Sociobiol 62:363-375

> Trillmich F, Rea L, Castellini M, Wolf JBW (2008) Agerelated changes in hematocrit in the Galápagos sea lion (Zalophus wollebaeki) and the Weddell seal (Leptonychotes weddellii). Mar Mamm Sci 24:303-314

Trites AW, Donnelly CP (2003) The decline of Steller sea 
lions Eumetopias jubatus in Alaska: a review of the nutritional stress hypothesis. Mammal Rev 33:3-28

Trivers RL (1974) Parent-offspring conflict. Am Zool 14: 249-264

> Verrier D, Guinet C, Authier M, Tremblay Y and others (2011) The ontogeny of diving abilities in subantarctic fur seal pups: Developmental trade-off in response to extreme fasting? Funct Ecol 25:818-828

Villegas-Amtmann S, Costa DP (2010) Oxygen stores plasticity linked to foraging behaviour and pregnancy in a diving predator, the Galapagos sea lion. Funct Ecol 24:785-795

Villegas-Amtmann S, Costa DP, Tremblay Y, Salazar S, Aurioles-Gamboa D (2008) Multiple foraging strategies in a marine apex predator, the Galapagos sea lion Zalophus wollebaeki. Mar Ecol Prog Ser 363:299-309

Weathers WW, Sullivan KA (1989) Juvenile foraging proficiency, parental effort, and avian reproductive success. Ecol Monogr 59:223-246

Editorial responsibility: Peter Corkeron, Woods Hole, Massachusetts, USA
Weise MJ, Costa DP (2007) Total body oxygen stores and physiological diving capacity of California sea lions as a function of sex and age. J Exp Biol 210:278-289

- Weise MJ, Harvey JT, Costa DP (2010) The role of body size in individual-based foraging strategies of a top marine predator. Ecology 91:1004-1015

Werner EE, Gilliam JF (1984) The ontogenetic niche and species interactions in size-structured populations. Annu Rev Ecol Syst 15:393-425

Wikelski M, Trillmich F (1994) Foraging strategies of the Galapagos marine iguana (Amblyrhynchus cristatus): adapting behavioral rules to ontogenetic size change. Behaviour 128:255-279

York AE, Thomason JR, Sinclair EH, Hobson KA (2008) Stable carbon and nitrogen isotope values in teeth of Steller sea lions: age of weaning and the impact of the 1975-1976 regime shift in the North Pacific Ocean. Can J Zool 86:33-44

Submitted: October 7, 2011; Accepted: January 31, 2012 Proofs received from author(s): April 19, 2012 